\title{
Rapid bone repair in a patient with lung cancer metastases to the spine using a novel herbal medicine: A case report
}

\author{
RONG PU ${ }^{1}$, QIANHONG ZHAO ${ }^{1}$, ZHIMEI LI ${ }^{2}$, LINGYAN ZHANG ${ }^{1}$, XIAOLU LUO ${ }^{2}$, \\ YANGJI ZEREN ${ }^{2}, \mathrm{CUI} \mathrm{YU}^{3}$ and XIANYONG LI ${ }^{1}$ \\ Departments of ${ }^{1}$ Oncology, ${ }^{2}$ Nursing and ${ }^{3}$ Radiology, Chengdu Fuxing Hospital, Chengdu, Sichuan 610036, P.R. China
}

Received April 4, 2015; Accepted May 19, 2016

DOI: $10.3892 / \mathrm{ol} .2016 .4879$

\begin{abstract}
The prognosis of lung carcinoma with metastasis to the bone, particularly to the spine, is poor. Chemotherapy and radiotherapy are established treatments for metastatic bone disease, but their effectiveness is unsatisfactory and bone repair following their use is slow and difficult. Medicine prepared from herbal extracts may be an alternative treatment option. The present study discusses the case of a 59-year-old patient diagnosed with squamous cell lung cancer (T2N3M1) in which first-line chemotherapy using docetaxel plus cisplatin failed. Heavy multiple bone metastases were detected in the T9 vertebra and sixth left rib, resulting in a high risk of pathological fracture. Eastern Cooperative Oncology Group (ECOG) and numerical rating scale (NRS) scores of pain were 2 and 4, respectively. A second-line treatment was chosen consisting of biological intracontrol treatment (BICT) plus bisphosphonates administered over 40 days. BICT is a therapy involving the use of herbal extracts (including ginseng, herba agrimoniae, hairyvein agrimonia herb, white flower patrinia herb and arginine) and palliative care. A partial positive response was reached following use of this regimen, particularly with regard to bone repair. A computed tomography scan revealed a $90 \%$ reduction in the broken area of the rib cage and $\mathrm{T} 9$ vertebra. The bone repair was rapid and almost complete. In addition, growth of the primary tumor in the right pulmonary hilar and metastasis in the mediastinal lymph nodes were stabilized following treatment. ECOG and NRS scores were decreased
\end{abstract}

Correspondence to: Professor Xianyong Li, Department of Oncology, Chengdu Fuxing Hospital, Houjia, Tuqiao, Jinniu, Chengdu, Sichuan 610036, P.R. China

E-mail: 1xy1956@yeah.net

Abbreviations: BICT, biological intracontrol treatment; CT, computed tomography; ECOG, eastern cooperative oncology group; EGFR, epidermal growth factor receptor; NRS, numerical rating scale; PD-1, programmed cell death protein 1; QOL, quality of life; TGF, transforming growth factor; VEGFR, vascular endothelial growth factor receptor

Key words: lung cancer, bone metastasis, rapid repair, herbal medicine, biological intracontrol treatment to 1 and 0 , respectively, leading to an improved quality of life. Based on these results, the present study suggests that this herbal medicine-based regimen promotes bone repair and inhibits tumor growth, with low toxicity. However, the mechanism by which herbal medicine promotes rapid bone repair is unclear. Further studies are required to determine whether cells in the tumor microenvironment are stimulated to undergo re-differentiation by unidentified herbal substances.

\section{Introduction}

Approximately 20,000 new cases of bone metastasis are diagnosed each year. The most common site for bone metastasis is the spine, with up to $70 \%$ of cancer patients developing spinal lesions (1). The prognosis of patients with lung cancer metastasis to the spine is poor, with a reported 5 -year survival rate of 10 to $20 \%$ (2). Treatment options include surgery, radiation, chemotherapy and rehabilitative medicine $(3,4)$. In general, the life expectancy of a patient should exceed 3 months in order that surgical intervention may be considered. Similarly, a life expectancy of $>1$ month is necessary for the consideration of radiation treatment $(3,5)$. In cases of adenocarcinoma with bone metastasis, epidermal growth factor receptor (EGFR) inhibitors can improve the prognosis (6). However, for squamous cell lung cancer patients who refuse chemotherapy and surgery due to the side effects and risks, respectively, the development of effective anticancer compounds and palliative treatments with low toxicity is critical for the treatment of unresectable spinal metastasis.

In the present study, a systemic therapy, biological intracontrol treatment (BICT) was administered to a lung cancer patient with multiple bone metastases. BICT consists of a combination of early palliative care and herbal extract combinations, including ginseng, herba agrimoniae, hairyvein agrimonia herb, white flower patrinia herb and arginine, provided by the Chinese State Food and Drug Administration. As herbal extract combinations are extracted from natural compounds, it exhibits low toxicity and is typically used for inhibiting cancer growth and improving quality of life (QOL). In our previous studies, this drug combination was able to inhibit EGFR and vascular endothelial growth factor receptor (VEGFR) expression, decrease microvessel density, inhibit expression of interleukin (IL)-10 and transforming growth factor (TGF)- $\beta$ in the tumor microenvironment, and promote apoptosis $(7,8)$. 
A

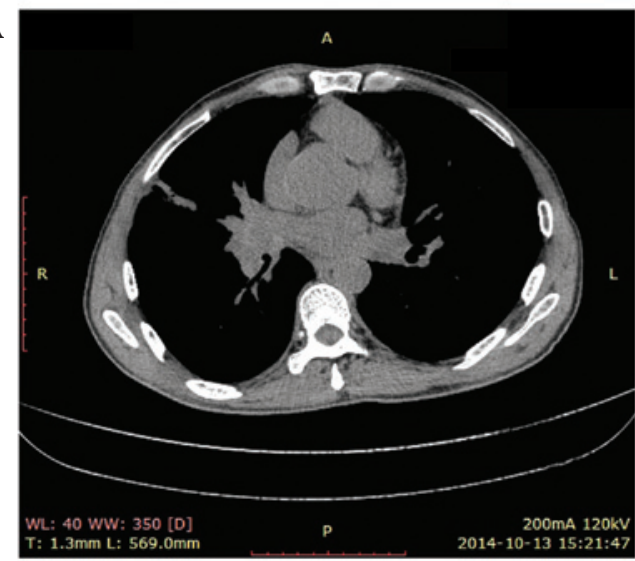

C

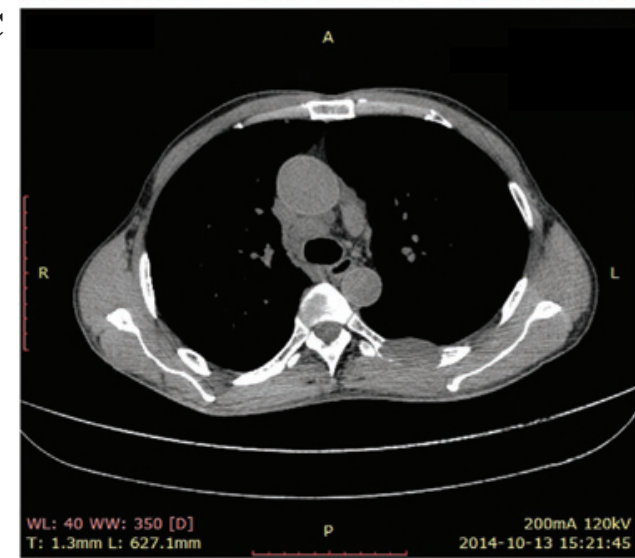

$\mathbf{B}$

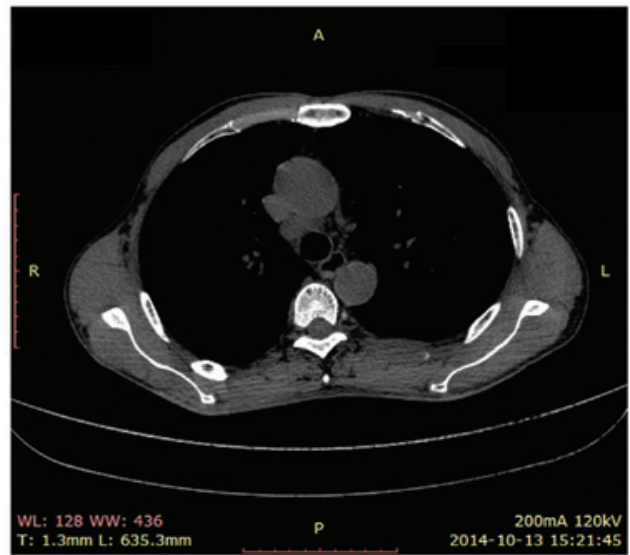

D

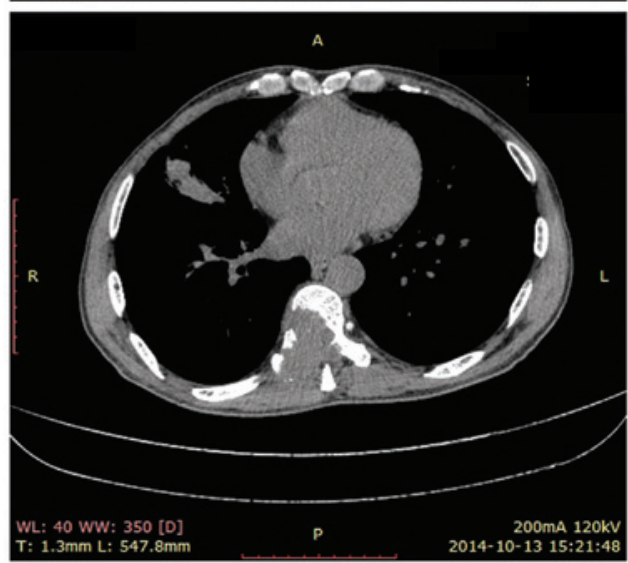

Figure 1. Evaluation of the patient by CT prior to treatment on October 13, 2014. (A) CT scan revealing a solid mass in the region of the right pulmonary hilum that measured $\sim 5.0 \times 4.0 \mathrm{~cm}$. (B) CT scan revealing a solid mass in the mediastinal lymph node that measured $\sim 2.2 \times 1.4 \mathrm{~cm}$. (C) CT scan revealing a solid mass that measured $\sim 3.5 \times 2.0 \mathrm{~cm}$ and damaged the back of sixth left rib near the T6 vertebra. (D) CT scan revealing a solid mass in the region of the T9 vertebra, which damaged the T9 vertebra. CT, computed tomography.

\section{Case report}

A 59-year-old male who attended GuangYuan Traditional Chinese Medicine Hospital (GuangYuan, China) was diagnosed with pathologically confirmed squamous cell lung cancer on 24th September, 2014, accompanied by failure of the first-line treatment regimen of docetaxel $\left(75 \mathrm{mg} / \mathrm{m}^{2}\right)$ plus cisplatin $\left(40 \mathrm{mg} / \mathrm{m}^{2}\right)$ after just one cycle and the development of serious side effects, which began two days after diagnosis. Multiple bone metastases occurred in the sixth left rib and T9 vertebra, resulting in a high risk of pathological fracture and disability. The cancer was diagnosed as National Comprehensive Cancer Network T2N3M1, stage IV (9). Eastern Cooperative Oncology Group (ECOG) (10) and numerical rating scale (NRS) scores (11) of pain were 2 and 4 , respectively. The patient described pain at his back around the T9 vertebral area. A physical examination revealed that the respiratory volume was decreased in each lung. A large solid mass was palpable at the back of the sixth left rib near the T6 thoracic vertebra, and percussion of the right side of the back around the T9 vertebra caused pain. Laboratory examination findings were as follows: White blood cell count, $2.9 \times 10^{9} / 1$ [normal range, (4.0-10.0) $\times 10^{9} / 1$ ]; alanine aminotransferase, $45.6 \mathrm{U} / 1$ (normal range, 0-40 U/l); aspartate aminotransferase, $32 \mathrm{U} / 1$ (normal range, 0-49 U/1); alkaline phosphatase, $44 \mathrm{U} / 1$ (normal range, 34-114 U/l); serum $\mathrm{Ca}^{2+}, 2.07 \mathrm{mmol} / \mathrm{l}$ (normal range, 2.03-2.54 mmol/1); carcinoembryonic antigen, $1.53 \mathrm{U} / \mathrm{ml}$ (normal range, 0-5 ng/ml); and CYFRA-211, $42.9 \mathrm{U} / \mathrm{ml}$ (normal range, $0-7 \mathrm{ng} / \mathrm{ml})$. Computed tomography $(\mathrm{CT})$ scans performed on October 13, 2014, revealed abnormal masses at the right pulmonary hilum (Fig. 1A), the mediastinal lymph node (Fig. 1B) and the sixth left rib near the T6 vertebra (Fig. 1C), measuring 5.0x4.0, 2.2x1.4 and $3.5 \times 2.0 \mathrm{~cm}$, respectively. The T9 vertebra appeared to be nearly completely replaced by a neoplasm measuring $4.7 \times 4.9 \mathrm{~cm}$. (Fig. 1D).

Although the patient received only one cycle of chemotherapy, the tumor progressed and the patient refused to receive any further chemotherapy or radiation therapy. The patient was weak with an ECOG score of 3; thus, low toxicity drugs and palliative treatment were recommended. Herbal medicine and bisphosphonate treatments were selected as anticancer treatment and palliative care, respectively. Herbal extract combinations were administered orally four times daily, including Shenghuang capsule $(0.8 \mathrm{~g})$, Xianhe Baijiang capsule $(1.2 \mathrm{~g})$ and arginine liquid $(15 \mathrm{ml})$, and a single dose of bisphosphonate was administered mid-treatment. Furthermore, hyperthermia was applied to the cancer mass area to enhance drug absorption and kill the cancer cells directly, and the patient was asked to discontinue heavy exercise to prevent a pathological fracture of the T9 vertebra. After 40 days of treatment, a CT scan revealed a significant decrease in the size of the masses in the T9 vertebra and the sixth left rib in the long axis, and no new growth in the right pulmonary hilum and mediastinal lymph node, with masses now measuring $3.8 \times 3.1$ and $1.8 \times 1.3 \mathrm{~cm}$, respectively. Additionally, no new 
A

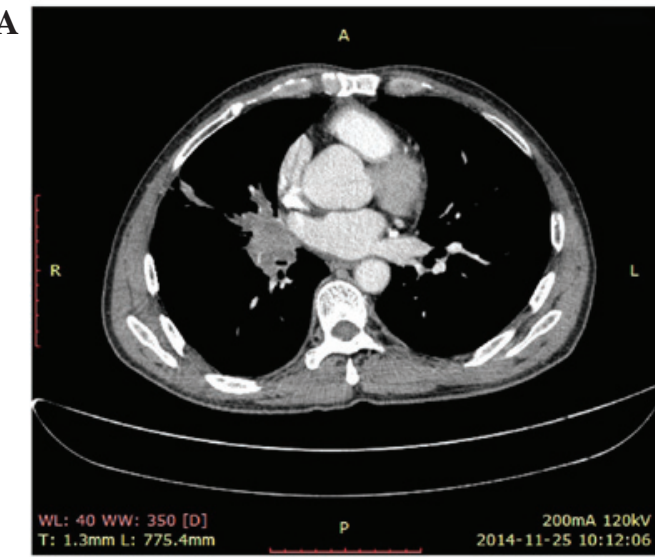

C

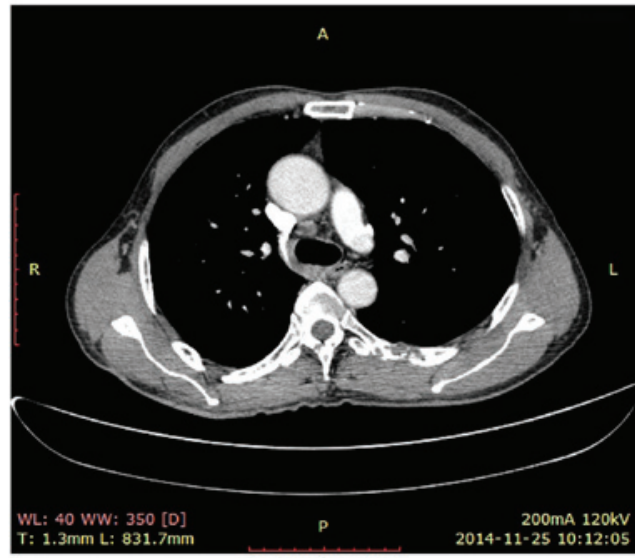

B

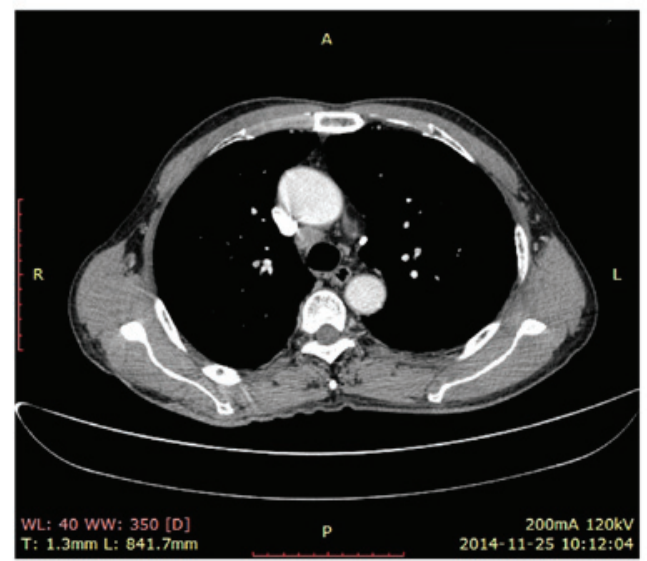

D

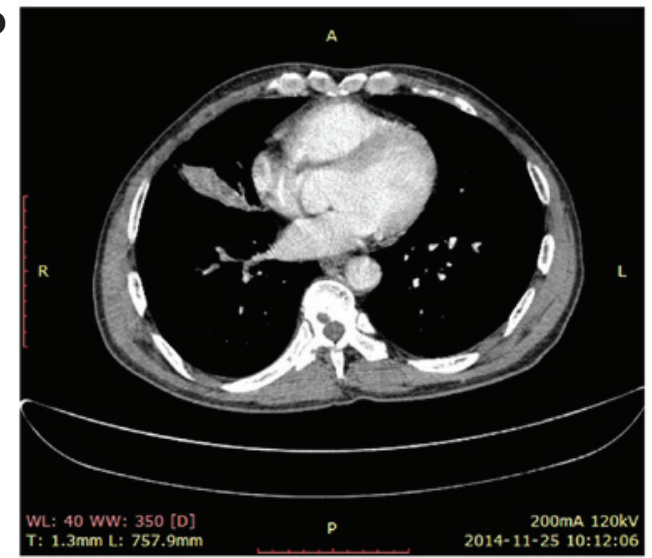

Figure 2. Evaluation of the patient by CT at 40 days post-treatment on November 25, 2014. (A and B) CT scan revealing a solid mass in the region of the right pulmonary hilum and mediastinal lymph node, and no new masses in the lung. (C and D) CT scans revealing that the bone damage in the region of the T9 vertebra and the back of the sixth left rib had been almost completely repaired when compared with the scan on October $13,2014$.
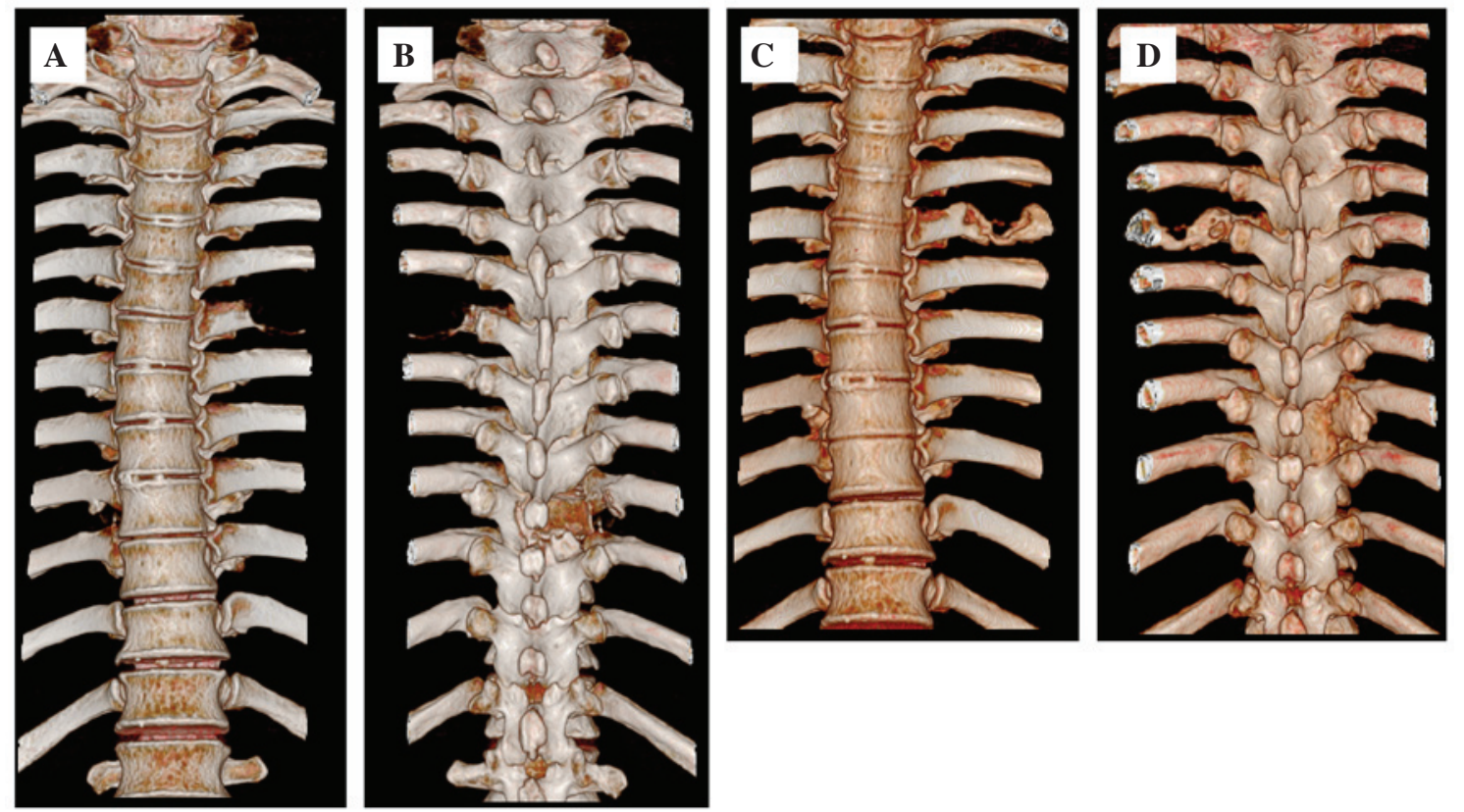

Figure 3. (A and B) CT scan showed the 3-dimensional structure of the T9 vertebra and the back of the sixth left rib prior to treatment on October 13 , 2014 (C and D) CT scan revealed the 3-dimensional reconstruction of the T9 vertebra and the back of the sixth left rib following treatment on November $25,2014$.

metastatic masses were detected (Fig. 2). Meanwhile, the QOL of the patient had improved, and the ECOG and NRS scores of pain had decreased to 1 and $0-1$, respectively.
The patient continued to be monitored through follow-up appointments. After 40 days post-treatment, on November 25, 2014, a second CT scan revealed decreases of 20 and $95 \%$ in 
the masses of the T9 vertebra and sixth left rib, respectively. Additionally, rapid bone repair was evident (Figs. 2 and 3). These results were accompanied by clinical and QOL improvements, the restoration of tumor marker levels to normal values and stabilization of the tumor masses. A partial response was achieved according to the guidelines outlined in the Response Evaluation Criteria in Solid Tumors (12), and the clinical response was confirmed by $\mathrm{CT}$ tests. Furthermore, a blood test confirmed that the white blood cells had recovered to $6.9 \times 10^{9} / 1$, alanine aminotransferase levels to $36.9 \mathrm{U} / \mathrm{l}$ and aspartate aminotransferase levels to $30 \mathrm{U} / \mathrm{l}$. According to Common Terminology Criteria for Adverse Events version 3.0, no vomiting or hematological toxicity of more than grade 1 severity was observed.

The patient was monitored regularly for 8 months from the start of BICT treatment (11th October, 2014), but was subsequently lost to follow-up after May 2015.

\section{Discussion}

The spine is one of the most common sites for bone metastasis, and the thoracic spine is the most common site for spinal metastasis in lung cancer. CT scans can recognize a bony metastatic lesion up to 6 months earlier than radiography. However, pathological compression fractures, which are common in metastatic disease, can be readily observed, yielding a detection rate of bone metastasis on plain radiography of $\sim 40 \%$ (13).

Vertebral metastases cause chronic and increasing pain, and neurological deficits due to destruction of the vertebral body, thus increasing the risk of a pathological fracture (14). Commonly, palliative surgery and local radiation therapy are employed. In the treatment of spinal metastases, palliative surgery aims to reduce pain, and maintain neurological function and spinal stability (14). Palliative radiation therapy is often administered at $30 \mathrm{~Gy}$ in 10 fractions by a 6-MV X-ray (15-17). Recently, programmed cell death protein 1 (PD-1) and its ligands, programmed cell death 1 ligands 1 and 2, have been shown to play important roles in treating melanoma and lung cancers (18).

Pembrolizumab and nivolumab, two humanized monoclonal antibodies targeting PD-1, have had success in treating non-small cell lung cancer and are currently being tested in multiple other tumor types $(19,20)$. Nivolumab is currently approved by the FDA as a second-line therapy for squamous cell lung cancer, demonstrating an objective response rate of $14.5 \%$ and a median time to response of 3.3 months $(21,22)$. However, for patients classified as having an ECOG performance status of 3-4, no standard chemotherapy regimen has been established, owing to the associated high toxicity and low effectiveness of these drugs. For these patients, individual care is commonly employed. In the present case, a medicine comprised of extracts of a combination of several herbs, plus bisphosphonates, not only inhibited tumor growth, but also stimulated significant and rapid bone repair. These results suggest previously unknown properties of this combination of herbal extracts.

In our previous studies $(7,8)$, this combination of herbal extracts inhibited EGFR/VEGFR, IL-10 and TGF- $\beta$ expression in the tumor microenvironment, and increased serum IL-12 expression. EGFR/VEGFR, IL-10 and TGF- $\beta$ are pro-inflammatory cytokines that promote cancer growth, whereas IL-12 functions to inhibit cancer growth. Treatment with the herbal combination resulted in decreased microvessel density in the tumor microenvironment and increased tumor cell apoptosis. Although this may explain the inhibition of cancer growth observed in the present patient, the mechanism by which the herbal medication promotes rapid bone repair remains under investigation.

In conclusion, the present study describes a case in which herbal medicine promoted tumor regression and bone repair, with an improved QOL in a short period of time. It is unclear whether the combination of herbal medicine and bisphosphonates synergistically enhanced bone repair. The study demonstrated a novel individualized approach to treat lung cancer patients with an ECOG performance status of 3 or higher. Further research is necessary to determine the mechanisms underlying the effectiveness of herbal combination medicine plus bisphosphonates and the benefits associated with this treatment.

\section{References}

1. American Association of Neurological Surgeons: Patient Information, Spinal Tumors. http://www.aans.org/en/Patient $\% 20$ Information/Conditions $\% 20$ and $\% 20$ Treatments/Spinal $\% 20$ Tumors.aspx (accessed July 2014).

2. Sundaresan N, Boriani S, Rothman A and Holtzman R: Tumors of the osseous spine. J Neurooncol 69: 273-290, 2004.

3. Sciubba DM, Petteys RJ, Dekutoski MB, Fisher CG, Fehlings MG, Ondra SL, Rhines LD and Gokaslan ZL: Diagnosis and management of metastatic spine disease. A review. J Neurosurg Spine 13: 94-108, 2010.

4. Dodwad SN, Savage J, Scharschmidt TJ and Patel A: Evaluation and treatment of spinal metastatic disease. Cancer Treat Res 162: 131-150, 2014.

5. Tokuhashi Y, Ajiro Y and Umezawa N: Outcome of treatment for spinal metastases using scoring system for preoperative evaluation of prognosis. Spine (Phila Pa 1976) 34: 69-73, 2009.

6. Sugiura H, Yamada K, Sugiura T, Hida T and Mitsudomi T: Predictors of survival in patients with bone metastasis of lung cancer. Clin Orthop Relat Res 466: 729-736, 2008.

7. Li X, Zhang L and Li Y: Inhibition of cancer cell proliferation by color modulation: A pilot study. Presented at the JSMO, Japan 2013.

8. Li X, Li J, Tian Y, Zhang L, Liu H, Li Z and Yin W: Inhibition of rectal cancer growth by a new herbal extract combinations (FUO-C4) in vivo. Presented at the JSMO, Japan 2014.

9. National Comprehensive Cancer Network Non-small Lung Cancer Guidelines. https://www.ncen. org/store/login/login.aspx?ReturnURL=https://www.nccn. org/professionals/physician_gls/pdf/nscl.pdf, 2015.

10. Oken MM, Creech RH, Tormey DC, Horton J, Davis TE, McFadden ET and Carbone PP: Toxicity and response criteria of the Eastern Cooperative Oncology Group. Am J Clin Oncol 5: 649-655, 1982.

11. Dworkin RH, Turk DC, Farrar JT, Haythornthwaite JA, Jensen MP, Katz NP, Kerns RD, Stucki G, Allen RR, Bellamy N, et al: Core outcome measures for chronic pain clinical trials: IMMPACT recommendations. Pain 113: 9-19, 2005.

12. Trotti A, Colevas AD, Setser A, Rusch V, Jaques D, Budach V, Langer C, Murphy B, Cumberlin R, Coleman CN and Rubin P: CTCAE v3.0: Development of a comprehensive grading system for the adverse effects of cancer treatment. Semin Radiat Oncol 13: 176-181, 2003.

13. Salvo N, Christakis M, Rubenstein J, de Sa E, Napolskikh J, Sinclair E, Ford M, Goh P and Chow E: The role of plain radiographs in management of bone metastases. J Palliat Med 12: 195-198, 2009.

14. Xu S, Yu X and Xu M: Long-term survival of a patient with lung cancer metastasis to the spine following surgical treatment combined with radiation and epithelial growth factor receptor inhibitor therapy: A case report. Exp Ther Med 9: 117-119, 2015. 
15. Hartsell WF, Scott CB, Bruner DW, Scarantino CW, Ivker RA, Roach M III, Suh JH, Demas WF, Movsas B, Petersen IA, et al: Randomized trial of short-versus long-course radiotherapy for palliation of painful bone metastases. J Natl Cancer Inst 97: 798-804, 2005.

16. No authors listed: 8 Gy single fraction radiotherapy for the treatment of metastatic skeletal pain: Randomised comparison with a multifraction schedule over 12 months of patient follow-up. Bone Pain Trial Working Party. Radiother Oncol 52: 111-121, 1999.

17. Zhao F, Ding G, Huang W, Li M, Fu Z, Yang G, Kong L, Zhang Y and Yu J: FDG-PET predicts pain response and local control in palliative radiotherapy with or without systemic treatment in patients with bone metastasis from non-small-cell lung cancer. Clin Lung Cancer 16: e111-e119, 2015.

18. Azoury SC, Straughan DM and Shukla V: Immune Checkpoint Inhibitors for Cancer Therapy: Clinical Efficacy and Safety. Curr Cancer Drug Targets 15: 452-462, 2015.
19. Garon EB, Rizvi NA, Hui R, Leighl N, Balmanoukian AS, Eder JP, Patnaik A, Aggarwal C, Gubens M, Horn L, et al; KEYNOTE-001 Investigators: Pembrolizumab for the treatment of non-small-cell lung cancer. N Engl J Med 372: 2018-2028, 2015.

20. Brahmer J, Reckamp KL, Baas P, Crinò L, Eberhardt WE, Poddubskaya E, Antonia S, Pluzanski A, Vokes EE, Holgado E, et al: Nivolumab versus Docetaxel in Advanced Squamous-Cell Non-Small-Cell Lung Cancer. N Engl J Med 373: 123-315, 2015.

21. Rizvi NA, Mazières J, Planchard D, Stinchcombe TE, Dy GK, Antonia SJ, Horn L, Lena H, Minenza E, Mennecier B, et al: Activity and safety of nivolumab, an anti-PD-1 immune checkpoint inhibitor, for patients with advanced, refractory squamous non-small-cell lung cancer (CheckMate 063): A phase 2, single-arm trial. Lancet Oncol 16: 257-265, 2015.

22. McDermott J and Jimeno A: Pembrolizumab: PD-1 inhibition as a therapeutic strategy in cancer. Drugs Today (Barc) 51: 7-20, 2015. 